\title{
Use of Continuous-Flow Sequencing Batch Biofilm Reactor (CSBBR) for Wastewater Treatment
}

\author{
Abdelsalam Elawwad, Ahmed Sallam, Hisham Abdel-Halim \\ Environmental Engineering Dept., Faculty of Engineering, Cairo University \\ El-Gamaa St., 12613 Giza, Egypt \\ elawwad@cu.edu.eg, ahmdsallamsallam@gmail.com, hisham@enviroconsult-eg.com
}

\section{Extended Abstract}

Wastewater with high levels of pollutants causes several problems, such as eutrophication, oxygen consumption and toxicity, when discharged to the environment. It is, therefore, necessary to remove these substances from wastewaters for reducing their harm to the environment [1]. SBR system is recommended for small sanitation systems because of its simple configuration where it allows both biological processes and settling to occur in a single reactor [2]. Continuous flow SBR (CSBR) used in this study is a modified version of SBR in which flow enters the basin continuously, requires less control and has a simple configuration compared with the original SBR [2, 3]. In this research, two pilot plants (R1 and R2) were constructed and operated to compare the continuous-flow sequencing batch reactor (CSBR) and the continuousflow sequencing batch biofilm reactor (CSBBR) and to study its performance towards wastewater treatment. The experimental work was conducted at Zenien WWTP through different 4 stages: The first stage (start-up) carried out in 49 days, the second stage (Low organic load) carried out in 21 days, the third stage (Low organic with added media in R2) carried out in 70 days, and the fourth stage (medium organic load with added media in R2) carried out in 84 days, respectively. Thus, the pilot plants have been operated for 224 continuous days. Temperature was between $\left(16.1-33^{\circ} \mathrm{C}\right)$, and $\mathrm{pH}(6.00-$ 7.84). The media used during the third \& fourth stages is polyethylene HDPE BioPac Media with a specific surface area of $600 \mathrm{~m} 2 / \mathrm{m} 3$ and have been occupied $30 \%$ of the reactor volume. The solid retention time (SRT) was adjusted to be 15 days for all stages, flow rate was $(10 \mathrm{~L} / \mathrm{Hr}$.), and hydraulic retention time (HRT) was $(6 \mathrm{hrs}$.) for all stages. During the low organic load period, BOD, COD and TSS removal efficiencies in CSBR were 83.4\%, 83.4\% and 77.0\%, respectively, while in CSBBR were $94.0 \%, 89.0 \%$ and $85.0 \%$, respectively. During the medium organic load period, BOD, COD and TSS removal efficiencies were $80.3 \%, 80.0 \%$ and $77.5 \%$, respectively in CSBR, while in CSBBR were 90.1\%, 92.2\% and 82.0, respectively. Average concentrations of MLSS were $1471.96 \mathrm{mg} / \mathrm{l}$ and $1350.54 \mathrm{mg} / \mathrm{l}$ for CSBR and CSBBR, respectively and MLVSS concentrations were $1276.54 \mathrm{mg} / \mathrm{l}$ and $1173.70 \mathrm{mg} / \mathrm{l}$ for CSBR and CSBBR, respectively. For nitrogen removal, CSBBR showed a bit higher efficiency than CSBR. In conclusion, CSBBR reactor showed higher efficiency and stability than the CSBR reactor due to the existence of media. The organic removal rates have improved after media addition, and the pilot plant showed stability for the treatment process with load increases. Our future work will focus on studying the suitability of the proposed CSBBR system in small and rural sanitation systems which suffer from a lack of sanitation services especially in developing countries such as Egypt [4].

\section{References}

[1] Elawwad, A., Naguib, A., Abdel-halim, H., "Modeling of phenol and cyanide removal in a full-scale coke-oven wastewater treatment plant", Desalination and Water Treatment, 57 (52), pp. 25181-25193, 2016.

[2] Elawwad, A., Hazem, M. "Minimization of sludge production in an integrated UASB-continuous flow sequencing batch reactor system”, Desalination and Water Treatment, 91, pp. 206-213, 2017.

[3] Lin, S., Cheng, K., "A new sequencing batch reactor for treatment of municipal sewage wastewater for agricultural reuse”, Desalination, 133, pp. 41-51, 2001.

[4] Elawwad, A., Rageb, M., Abdel-Halim, H., "An economical, environmental and social comparison between vacuum and gravity sewers in decentralized sanitation systems, with Egypt as a case study," Journal of Water Sanitation and Hygiene for Development, vol. 5, no. 4, pp. 614-619, 2015. 